\title{
The Relationship Between Ageist Attitudes and Body Image in Women
}

\author{
Dr. Sangeeta Bhatia 1 iD $\triangle$, Ms. Ananya Singh 2 iD \\ ${ }^{1}$ Senior Research Fellow, ICSSR, Associate Professor, Department of Psychology, Gargi College, University of Delhi, Siri Fort Road, \\ New Delhi \\ ${ }^{2}$ Student, B.A. (hons) Applied Psychology, Il year, Gargi college, Siri Fort Road, New Delhi \\ $\triangle$ Corresponding Author: Dr. Sangeeta Bhatia, E-mail: sangeeta.bhatia@gargi.du.ac.in
}

\section{ARTICLE INFORMATION ABSTRACT}

Received: December 17, 2020

Accepted: February 08, 2021

Volume: 3

Issue: 2

DOI: $10.32996 /$ jhsss.2021.3.2.2

\section{KEYWORDS}

Ageism, body image, ageist attitudes, young adults, middle aged adults, older adults
This study aims to understand the relationship between ageist attitudes and body image concerns across women in three different age groups namely; young adults (17 to 21 years), middle aged adults (40 to 49 years) and older adults (60 to 82 years). Two scales, measuring body image and ageism, were administered on a sample of 48 women $(\mathrm{N}=48)$ with 16 women in each aforemen-tioned category. The results indicated that women in the older category experienced the highest body image concerns, followed by middle aged and young adults respectively. Attitudes to-wards ageism were assessed based on various dimensions. Ageist attitudes were moderate on most dimensions except for direct prejudice to age in young adults; 'Social distance' in middle aged adults and 'Stereotype content associated with age categories' in middle aged adults as well as older adults. The study has implications for understanding the status of depression, low self-esteem and other co-morbid variables as related to ageism. No significant relationship was found between ageist attitudes and body image.

\section{Introduction}

The German writer, Schilder (1935) was the first to write about the concept of body image. He used this concept to refer to the image of ourselves that we form in our head. Over time, this concept has been improvised to refer to "the picture we have in our minds of the size, shape and form of our bodies; and to our feelings concerning these characteristics and our constituent body parts" (Slade, 1988). Literature on body image has been moulded by applied clinical concerns dealing majorly with three spheres, i.e. 'neurological disorders', 'body image distortion' as noticed in sufferers of eating disorders and 'body dysmorphia' or delusional misperceptions. It is this last sphere of 'body dysmorphia' that this paper talks about (Slade 1994).

The human body undergoes numerous changes as a result of aging such as, loss of physical and mental abilities along with hair loss, appearance of wrinkles, loss of teeth etc. These natural bodily changes brought on by age are looked upon negatively in a culture which appreciates ageless beauty as a norm (Becker et al., 2013). Often, the older population finds itself pressurized to surpass this ideal beauty which has a lasting impact on their body image (Cash, 2002). People often hold the perception that old age reduces attractiveness and as a result tend to stereotype old people as being ugly (Palmore, 1999; Kite et al. 2005). Various research studies in the United States, South Asia and the Caribbean have found that words such as unattractive and unappealing are linked to aging (Tan et al., 2004)

Butler (1969) was the first to use the term 'ageism' to refer to age based discrimination. Since then, various researchers have studied the prevalence of age based discrimination and highlighted it's vices (Palmore,1999; Ciliberto, Levine and Arluke,1981; Riley and Riley,1989; Rodin and Langer,1980). Jankowskia et al. (2016) found that older adults feel the need to 'age gracefully' while dealing with changes naturally brought on with age. Hurd (1999) found an internalization of ageist beauty norms in older women even though they deemed health to be of a higher value to them than physical attractiveness. Social expectancy theory states that people's perception of others is affected by the culture which in turn, affects their self perceptions. With regards to

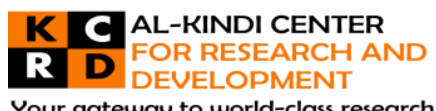

Your gateway to world-class research

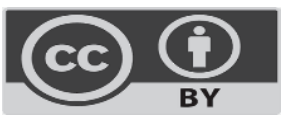

Published by Al-Kindi Center for Research and Development. Copyright (c) the author(s). This open access article is distributed under a Creative Commons Attribution (CC-BY) 4.0 license 
the societal focus on youthful beauty, perceived ageism may be related to low body esteem which may further relate to poor psychological well being (Sabik,2015). McContha et al., $(1999,2003)$ suggest that women experience higher anxiety due to aging than men because their self concept is closely related to their youthful appearance. Women with greater perceptions of age discrimination have been found to have lower body esteem (Sabik, 2015)

This paper investigates the relationship between ageist attitudes and body image concerns in women based on the hypothesis that women with a more ageist attitude would hold higher body image issues.

\section{Materials and methods}

A sample of 30 women (aged 17 to 82) was chosen based on the purposive sampling technique. These women belonged to an urban area and were from the middle income group. The age of the total sample varied from 17 to 82 . The young adult category had women between the ages of 17 to 21. The middle aged category consisted of women between the ages of 40 to 49 . The third category i.e. older adults included women between the ages of 60 to 82 . Most of the women were educated, with the highest education levels found in the middle aged category and the lowest in the older adults category.

Body Image Questionnaire, virtually similar to the Cosmetic Procedure Screening Questionnaire or COPS (Veale et. Al. 2012), was used to measure body image issues. BIQ had 22 questions. In the present study, only questions 8 to 19, based on a 9 point likert scale, were used. Total scores were achieved by summing up questions 8 to 19(only 18a and 19a were used). Scoring for questions 8,9 and 11 was reversed. Scores on the BIQ can range from 0 to 96 . Scores were interpreted such that higher the score, higher the body image concerns.

Core Indicator Set (CIS), developed by Vauclair, Abrams and Bratt (2010) was used to measure ageist attitudes. The CIS includes 23 questions (items 1 and 2 are objective in nature, item 3 is a multiple choice question and the rest are based on a likert scale) that assess ageist attitudes across nine dimensions: 'perceived permeability of age categories and boundaries, perceived status of age categories, social distance, perceived threat of age categories, stereotype content associated with age categories, direct prejudice towards age groups, experienced discrimination, contact with different age categories and seriousness of prejudice. An item wise analysis was carried out in order to assess ageist attitudes across these 9 dimensions.

For CIS, an item wise analysis was carried out in order to assess ageist attitudes across the 9 dimensions. The mean, standard deviation and correlation was later calculated for both the questionnaires for the total data as well as each sub group.

\subsection{Procedure}

Women belonging to the different age groups were contacted either online or in person and provided with online or offline questionnaires as applicable. 48 women returned both the questionnaires duly filled. Thus a purposive sample of 48 women was chosen $(\mathrm{N}=48)$. Out of this, 16 were grouped in the young adult category $(\mathrm{n} 1=16), 16$ were grouped in the middle aged category $(n 2=16)$ and the remaining 16 were grouped in the category of older adults ( $n 3=16)$. The data was collected in two rounds, post which the data analysis was done.

\section{Results and Discussion}

\section{Figure 1: Prevalence of body image concerns}

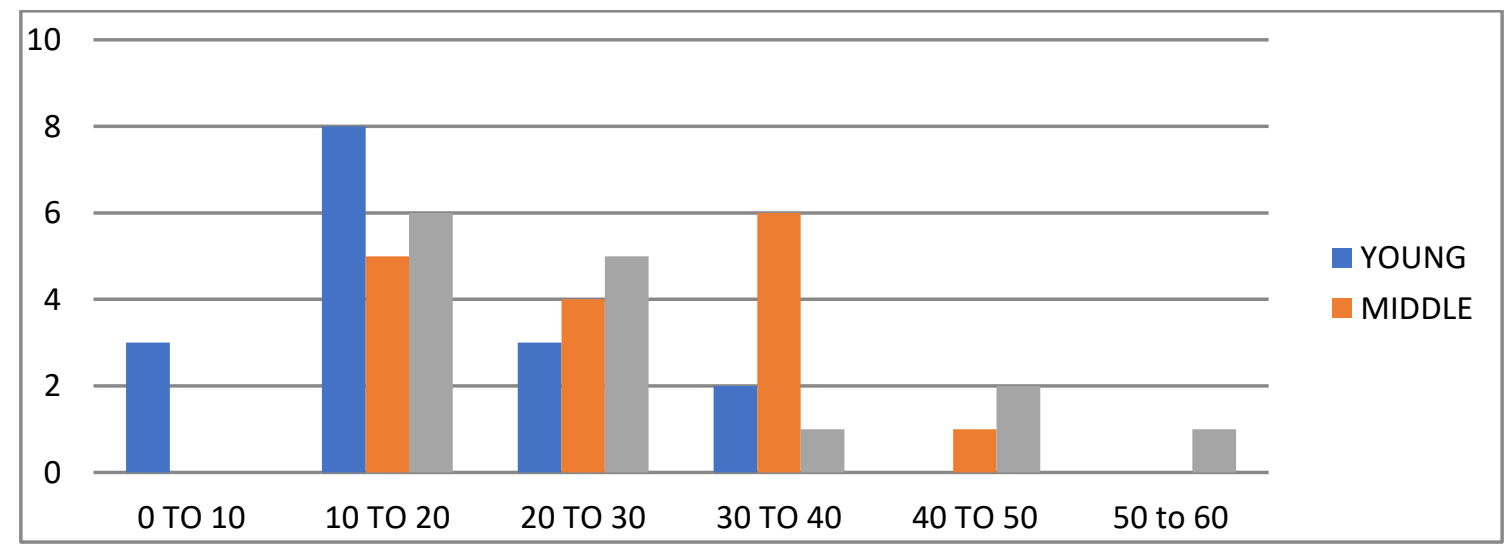

The diagram shows distribution of total scores on the BIQ. Young adults seem to have the lowest body image concerns whereas older adults have the highest body image concerns. Middle aged adults fare in the middle. 


\section{Figure 2: Distribution of total scores on the Core Indicator Set}

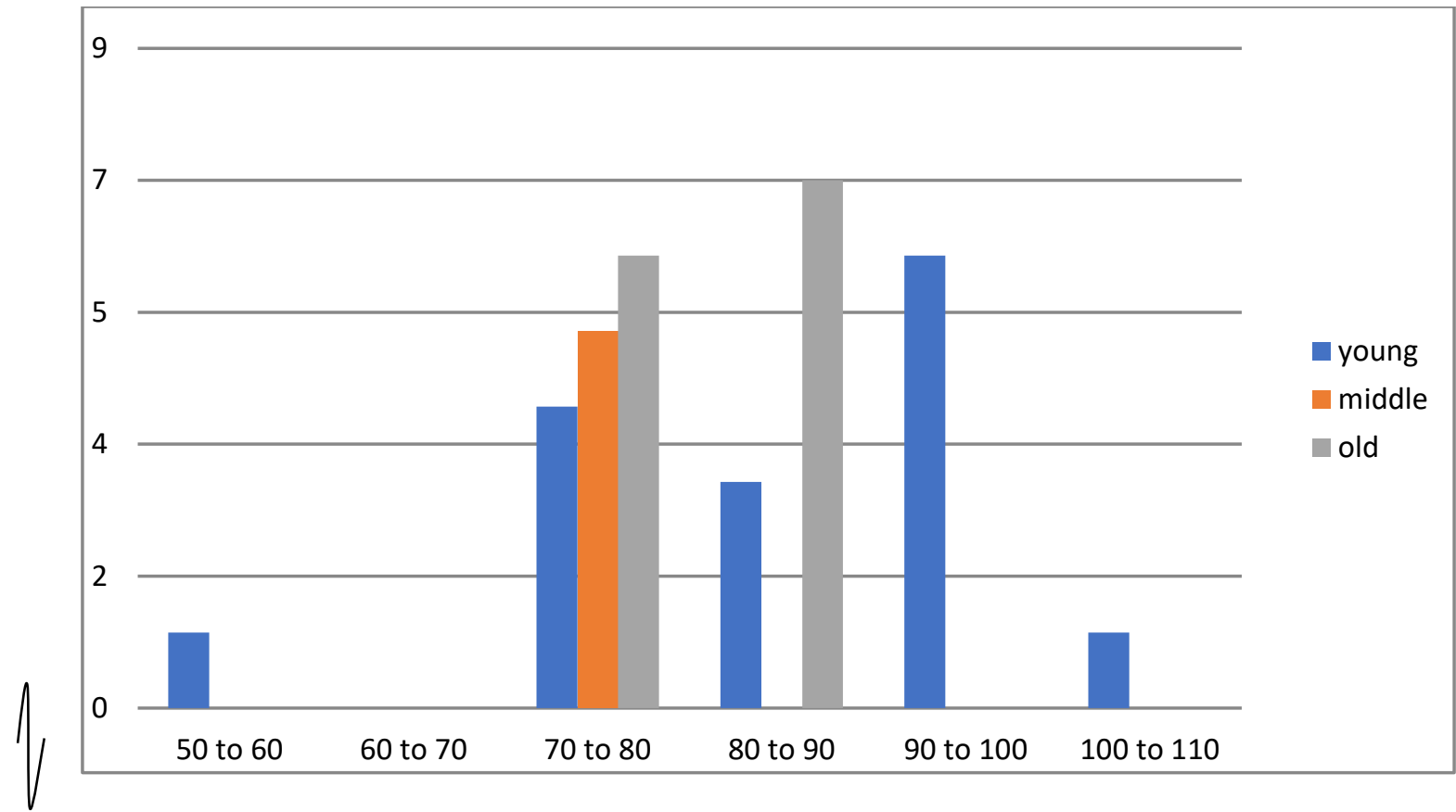

The scores of young adults are the most scattered with the highest and lowest scores both belonging to this category. The scores of Middle aged adults are in the middle between 70 and 100 . The scores of older adults lie in the range of 70 to 110 .

Table 1: Assessment of ageism in all the three age groups

\begin{tabular}{|c|c|c|c|c|c|c|c|}
\hline $\begin{array}{l}\text { Item } \\
\text { no. }\end{array}$ & $\begin{array}{l}\text { Norm } \\
\text { mean }\end{array}$ & $\begin{array}{l}\text { Mean } \\
\text { (young } \\
\text { adults) }\end{array}$ & $\begin{array}{l}\text { Range } \\
\text { (young } \\
\text { adults) }\end{array}$ & $\begin{array}{l}\text { Mean(middle } \\
\text { aged adults) }\end{array}$ & $\begin{array}{l}\text { Range(middle } \\
\text { aged adults) }\end{array}$ & $\begin{array}{l}\text { Mean(older } \\
\text { adults) }\end{array}$ & $\begin{array}{l}\text { Range } \\
\text { (older } \\
\text { adults) }\end{array}$ \\
\hline 1 & - & - & - & - & - & - & - \\
\hline 2 & - & - & - & - & - & - & - \\
\hline 3 & - & - & - & - & - & - & - \\
\hline 4 & 3.97 & 4.69 & Mid & 4.4 & Mid & 4.71 & Mid \\
\hline 5 & 5.09 & 4.88 & Mid & 4.63 & Mid & 4.75 & Mid \\
\hline 6 & 3.88 & 4.56 & Mid & 3.94 & Mid & 3.94 & Mid \\
\hline 7 & 3.51 & 3.88 & Mid & 4.75 & Mid & 4.13 & Mid \\
\hline 8 & 4.07 & 4.75 & Mid & 3.19 & Mid & 3.81 & Mid \\
\hline 9 & 4.13 & 4.5 & Mid & 5.38 & High & 4.69 & Mid \\
\hline 10 & 5.25 & 4.25 & Mid & 3.63 & Mid & 3.19 & Mid \\
\hline 11 & 2.85 & 3.56 & Mid & 3.25 & Mid & 4.13 & Mid \\
\hline 12 & 3.63 & 4.63 & Mid & 5.31 & High & 4.25 & Mid \\
\hline
\end{tabular}




\begin{tabular}{|l|l|l|l|l|l|l|l|}
\hline 13 & 3.88 & 4.88 & Mid & 4.88 & Mid & 4.19 & Mid \\
\hline 14 & 3.07 & 3.69 & Mid & 3.38 & Mid & 3.13 & Mid \\
\hline 15 & 5.08 & 4.31 & Mid & 4.38 & Mid & 5.06 & High \\
\hline 16 & 3.6 & 3.44 & Mid & 3.38 & Mid & 3.19 & Mid \\
\hline 17 & 5.62 & 6 & Mid & 5.94 & High & 5.63 & High \\
\hline 18 & 4.98 & 5.31 & High & 4.81 & Mid & 4.19 & Mid \\
\hline 19 & 4.82 & 4.69 & High & 4.94 & Mid & 4.94 & Mid \\
\hline 20 & 4.02 & 4.25 & Mid & 3.31 & Mid & 3.19 & Mid \\
\hline 21 & - & - & - & - & - & - & - \\
\hline 22 & - & - & - & - & - & - & - \\
\hline 23 & 3.71 & 4.07 & Mid & 4.31 & Mid & 4.06 & Mid \\
\hline
\end{tabular}

Most of the mean scores for lie in the mid range indicating moderate levels of ageism. High levels of ageism were found in 'direct prejudice towards age groups' in young category, 'Stereotype content associated with age categories' in middle aged and older category and 'Social distance' in middle aged category.

\section{Figure 3: Response for item no. 3 on the CIS}

(Taking all things into account, how you see those in their 20s and those over 70 ?

1. as a common group

2. as two separate groups who are a part of the same community

3. as two separate groups who are not a part of the same community

4. only as individuals rather than groups)

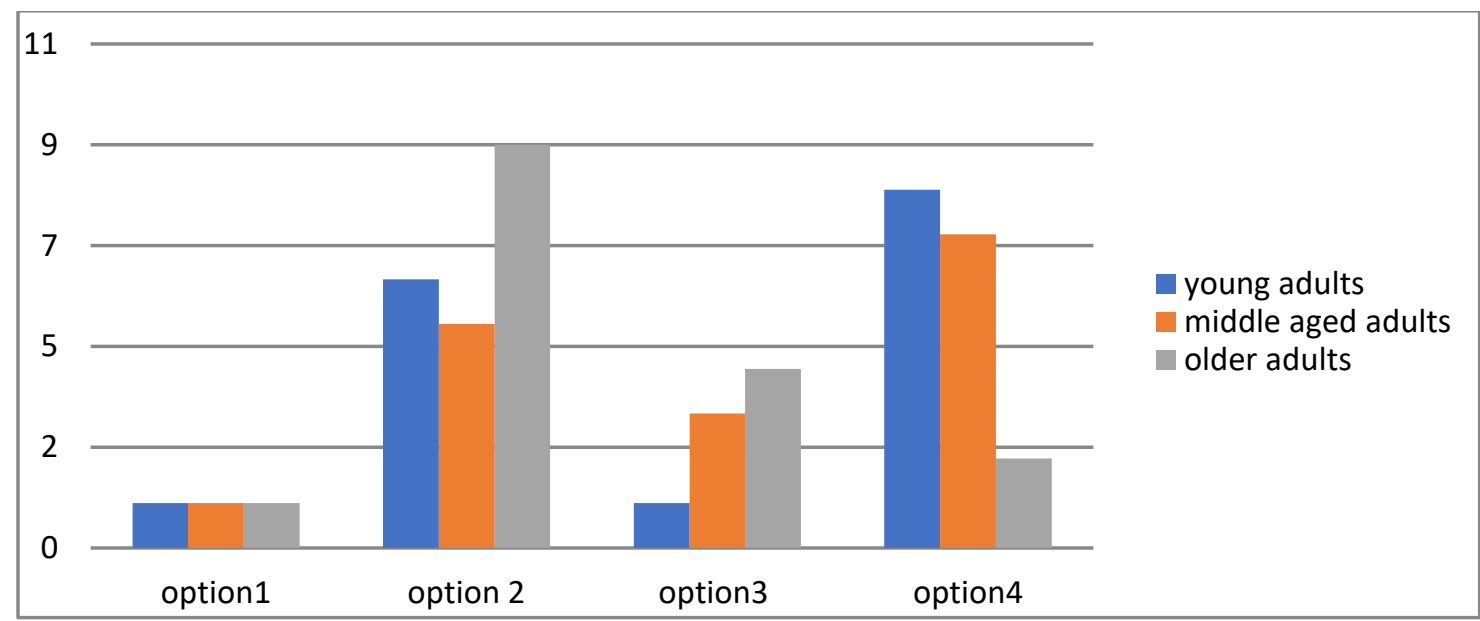

Responses of all three categories were scattered. Maximum no. of similar responses observed in the older category in agreement to option 2. 
Table 2: mean scores for items 21 and 22 on the CIS

Item 21: About how many friends or family members do you have who are younger than 30 and with whom you can discuss personal issues such as feelings, beliefs or experiences?

Item 22: About how many friends or family members do you have who are older than 70 and with whom you can discuss personal issues such as feelings, beliefs or experiences

\begin{tabular}{|l|l|l|}
\hline Category & Mean score on item 21 & Mean score on item 22 \\
\hline Young adults & 4.16 & 0.88 \\
\hline Middle aged adults & 2.41 & 1.88 \\
\hline Older adults & 2.63 & 2.13 \\
\hline
\end{tabular}

Young adults had maximum no. of friends below 30 whereas older adults had the maximum no. of friends above 70 . All three categories had more friends below 30 as compared to those over 70.

Table 3: Means and standard deviations of scores on BIQ and CIS

\begin{tabular}{|c|c|c|c|c|c|}
\hline \multirow[t]{2}{*}{ Age group } & \multirow[t]{2}{*}{ Sample size } & \multicolumn{2}{|c|}{ Body Image Questionnaire(BIQ) } & \multicolumn{2}{|c|}{ Core Indicator Set (CIS) } \\
\hline & & Mean & SD & Mean & SD \\
\hline Total & 48 & 23.94 & 12.53 & 84.60 & 10.51 \\
\hline Young adults & 16 & 16.06 & 8.05 & 87.97 & 13.00 \\
\hline Middle aged & 16 & 27.13 & 9.87 & 84.09 & 7.93 \\
\hline Older adults & 16 & 28.625 & 15.13 & 81.75 & 9.65 \\
\hline
\end{tabular}

On the BIQ, Young adults have the lowest mean scores. The mean for middle aged adults lies in the middle whereas older adults have the highest mean score. On the CIS, young adults have the highest mean, followed by middle aged and older adults respectively. The standard deviation scores show that the scores are scattered away from the mean.

\section{Table 4: Correlation between body image and ageist attitudes}

\begin{tabular}{|l|l|l|}
\hline Age group & Sample size & Correlation \\
\hline Total & 48 & -0.19 \\
\hline Young adults & 16 & -0.09 \\
\hline Middle aged adults & 16 & 0.03 \\
\hline Older adults & 16 & 0.01 \\
\hline
\end{tabular}

No significant correlations observed. 


\section{Conclusion}

This study aimed to explore the prevalence of body image concerns and ageism and any relationship that might exist between the two constructs in women across three age groups of young adults, middle aged adults and older adults.

This study revealed that older women had the highest body image issues compared to their younger counterparts. Most studies on body image have focused on the younger age bracket (Tiggemann, 2004). However, studies that have examined body image concerns in older women found that they continue to experience body image concerns as well (Bedford \& Johnson, 2005; Grippo \& Hill, 2008; Lewis \& Cachelin, 2001; Slevin, 2006, 2010; Stevens \& Tiggemann, 1998; Tiggemann, 2004; Tiggemann \& Lynch, 2001, Baker \& Gringart, 2009; Oberg \& Tornstam, 1999). Bedford and Johnson (2005) found that women find themselves under a strong social and internal pressure to attend to their appearances in order to avoid disapproval, and as a result, old age brings with it increased concerns to appear younger and more attractive, giving rise to body image issues.

Young adults displayed high ageist attitudes on the dimension of 'direct prejudice towards age'. Middle aged adults displayed high ageism in the dimensions of 'social distance' and 'stereotype content associated with age'. Older adults displayed high ageist attitudes on the dimension of 'stereotype content associated with age'. Moderate levels of ageist attitudes were found on rest of the dimensions in all three categories. Research has found widespread prevalence of ageist attitudes amonst people of all age groups (Rupp, Vondanovich, \& Crede, 2005; Stuart-Hamilton and Mahoney, 2003). Consistent with previous researches, young adults in this study reported old age to begin much sooner than their older counterparts and older adults reported old age to begin much later than their younger counterparts (Drevenstedt,1975; Tuckman \& Lorge 1953). Relative to the other two categories, the middle aged participants believed that youth ended sooner.Young adults had more friends below thirty whereas older adults had more friends in the age group above 70 as compared to the other two groups. However, all three categories had more friends in the younger category as compared to the older category. Overall, moderate levels of ageism were found on the rest of the dimensions indicating the prevalence of age based discriminatory attitudes in the sample.

This paper attempted to establish a relationship between body image and ageism but, no significant correlation was found between the two constructs. However, the results of this study must be interpreted carefully taking into account that the sample size was quite small, thus making generalizations difficult. Responses to some questions had been left blank in which case the responses had to be marked zero, which could have affected the results. This study has further implications for determining the relationship between depression and body image concerns in older adults. It is understood that our society values the ideals of youth and youthful appearance. Thus people would face ageism as their age increases and people who hold body image issues would be more ageist in their attitudes. Since older adults have the highest scores on body image questionnaires, low self esteem could be a causal factor for this relationship between depression and body image. It also sets further impetus for determining any relationships between ageism and body image concerns so as to plan interventions that take into consideration their socio emotional well being.

\section{References}

[1] Baker. L, Gringart E. (2009). Body image and self-esteem in older adulthood. Aging and Society. 29(6):977-995.

[2] Becker, C.B., Diedrichs, P.C., Jankowski, G., Werchan, C. 2013. I'm not just fat, I'm old:

[3] Has the study of body image talk overlooked "old talk?" The Journal of Eating

[4] Disorders 1, 1- 12.

[5] Bedford, J.L., Johnson, C.S. (2005). Societal influences on body image dissatisfaction in younger and older women. Journal of Women and Aging. 18(1):41-55.

[6] Butler, R. N. (1969). Age-ism: Another form of bigotry. The Gerontologist, 9(4 Part 1), 243-246.

[7] Cash, T.F., 2002. A "negative body image": Evaluating epidemiological evidence., In: Cash, T.F., Pruzinsky, T.E. (Eds.), Body Image: $A$ Handbook of Theory, Research, and Clinical Practice (pp 269-276). Guilford Press, New York.

[8] Drevenstedt, J. (1976). Perceptions of onsets of young adulthood, middle age, and old age. Journal of Gerontology, 31(1), 53-57.

[9] Grippo, K.P., Hill, M.S. (2008). Self-objectification, habitual body monitoring, and body dissatisfaction in older European American women: Exploring age and feminism and moderators. Body Image, 5(2):173-182.

[10] Hurd, L. C. (2000). Older women's body image and embodied experience: An exploration. Journal of Women \& Aging, 12(3-4), 77-97.

[11] Jankowski, G. S., Diedrichs, P. C., Williamson, H., Christopher, G., \& Harcourt, D. (2016). Looking age-appropriate while growing old gracefully: A qualitative study of aging and body image among older adults. Journal of Health Psychology, 21(4), 550-561.

[12] Kite, M.E., Stockdale, G.D., Whitley, B.E. \& Johnson, B.T. (2005). Attitudes toward younger and older adults: An updated meta-analytic review. Journal of Social Issues, 61(2), 241-266.

[13] Lewis, D.M., Cachelin, F.M. (2001). Body image, body dissatisfaction, and eating attitudes in midlife and elderly women. Eating Disorders, 9(1):29-39.

[14] McConatha, J. T., Schnell, F., \& McKenna, A. (1999). Description of older adults as depicted in magazine advertisements. Psychological Reports, 85, 1051-1056.

[15] McConatha, J. T., Schnell, F., Volkwein, K., Riley, L., \& Leach, E. (2003). Attitudes toward aging. A comparative analysis of young adults from the United States and Germany. International Journal of Aging and Human Development, 57(3), 203-215

[16] Oberg, P., Tornstam, L. (1999). Body images among men and women of different ages. Aging and Society, 19(5):629-644. 
[17] Palmore, E. B. (1999). Ageism: Negative and positive. SciRes Springer. NY

[18] Rupp, D.E., Vodanovich, S.J. \& Crede, M. (2005) The multidimensional nature of ageism: Construct validity and group differences. Journal of Social Psychology, 145(3), 335-362.

[19] Sabik, N. J. (2015). Ageism and body esteem: Associations with psychological well-being among late middle-aged African American and European American women. The Journals of Gerontology Series B: Psychological Sciences and Social Sciences, 70(2), 191-201.

[20] Schilder, P. (1935). The image and appearance of the human body. Kegan Paul

[21] Slade, P. D. (1988). Body image in anorexia nervosa. The British Journal of Psychiatry, 153(Suppl 2), $20-22$.

[22] Slade, P. D. (1994). What is body image? Behavior research and therapy, 32(5), 497-502.

[23] Slevin, K.F. (2006). The embodied experiences of old lesbians. In: Calasanti T.M, Slevin K.F, editors. Age matters: Realigning feminist thinking. New York: Routledge

[24] Slevin, K.F. (2010). If I had lots of money...I'd have a body makeover. Managing the aging body. Social Forces, 88(3):1003-1020

[25] Stevens, C., Tiggemann, M. (1998). Women's body figure preferences across the life span. The Journal of Genetic Psychology, 159(1), 94102.

[26] Stuart-Hamilton, I. \& Mahoney, B. (2003). The effects of aging awareness training on knowledge of, and attitudes toward, older adults. Educational Gerontology, 29, 251-260.

[27] Tan, P.P., Zhang, N.H. \& Fan, L. (2004) Students' attitudes toward the elderly in the People's Republic of China. Educational Gerontology, 30(4), 305-314.

[28] Tiggemann, M., Lynch, J.E. (2001). Body image across the life span in adult women: The role of self-objectification. Developmental Psychology, 37(2), 243-253.

[29] Tiggemann, M. (2004). Body image across the adult life span: Stability and change. Body Image, 1(1),29-41.

[30] Tuckman, J., \& Lorge, I. (1953). When does old age begin and a worker become old? Journal of Gerontology 8, 483-488.

[31] Vauclair, C. M., Abrams, D., \& Bratt, C. (2010). Measuring attitudes to age in Britain: Reliability and validity of the indicators. Department for Work and Pensions, UK. 